\title{
Laboratory measurement system for pre-corroded sensors devoted to metallic artwork monitoring
}

\author{
M. Faifer ${ }^{1}$, S. Goidanich ${ }^{2}$, C. Laurano ${ }^{1}$, C. Petiti $^{2}$, S. Toscani ${ }^{1}$, M. Zanoni ${ }^{1}$ \\ ${ }^{1}$ DEIB, Politecnico di Milano, Piazza Leonardo da Vinci 32, 20133 Milano (Italy) \\ 2 Department of Chemistry, Materials and Chemical Engineering "Giulio Natta", Politecnico di Milano, Piazza Leonardo da Vinci 32, \\ 20133 Milano (Italy)
}

\begin{abstract}
The monitoring of environmental corrosivity around works of cultural heritage is a key task in the field of both active and preventive conservation. In the case of metallic artworks, this task can be performed by means of coupons or sensors realised with the same materials as the artworks to be conserved. In this work, a measurement system for the development and testing of sensors for atmospheric corrosivity monitoring is presented. The metrological features of the measurement system operated in conjunction with a developed sensor are analysed. The sensor allows for considering the different corrosion behaviours due to the presence of corrosion layers on the object to be preserved. The first developed sensors are made of pre-corroded copper and their resistance is measured. The developed system allows for monitoring thickness loss of over $3 \mathrm{~nm}$ in the temperature range of $23^{\circ} \mathrm{C}-39^{\circ} \mathrm{C}$. The performed analysis demonstrated that the system presents an efficient laboratory setup for the development and characterisation of sensors for atmospheric corrosivity monitoring.
\end{abstract}

\section{Section: RESEARCH PAPER}

Keywords: Measuring system; corrosion; metallic artwork monitoring; heritage

Citation: Marco Faifer, Sara Goidanich, Christian Laurano, Chiara Petiti, Sergio Toscani, Michele Zanoni, Laboratory measurement system for pre-corroded sensors devoted to metallic artwork monitoring, Acta IMEKO, vol. 10, no. 1, article 28, March 2021, identifier: IMEKO-ACTA-10 (2021)-01-28

Editor: Ioan Tudosa, University of Sannio, Italy

Received May 4, 2020; In final form November 23, 2020; Published March 2021

Copyright: This is an open-access article distributed under the terms of the Creative Commons Attribution 3.0 License, which permits unrestricted use, distribution, and reproduction in any medium, provided the original author and source are credited.

Corresponding author: Marco Faifer, e-mail: marco.faifer@polimi.it

\section{INTRODUCTION}

The monitoring process plays a crucial role in the preservation of metallic artworks. In fact, whenever possible, the control of the various environmental parameters presents a critical step in the area of preventive conservation. Here, the real-time monitoring of environmental corrosivity is a particularly important tool for the appropriate preservation of works of art. Such an approach allows for not only checking whether the environment could be harmful to the artefacts but also for selecting the most appropriate conservation solutions. Here, metals may be particularly sensitive to any increase in relative humidity $(\mathrm{RH})$ or to the presence of specific pollutants in the atmosphere, such as low molecular weight carboxylic acids [1], [2]. However, while the monitoring of parameters such as humidity, temperature, and pollutants is a common practice [3][4], this does not necessarily provide specific information regarding the actual impact of the environment on the degradation rate of different materials. One possible solution is to expose both the object to be monitored and a sample made with the same alloy to the same environmental conditions. This approach also offers the opportunity to perform invasive measurements on the specimen without damaging the work of art [3]-[7].

Another possible approach involves the employment of environmental corrosivity sensors [7]-[9]. While for other fields of application, various different types of sensors have been reported [10]-[12], few solutions have been specifically designed for the cultural heritage field [7], [13]-[15]. In fact, the majority of the sensors proposed thus far, as well as the European standard for the classification of the corrosivity of atmospheres [16], do not consider the effect of the presence of corrosion layers on the surface. This is of particular importance when dealing with historic surfaces, which generally present a fairly complex stratigraphy of corrosion layers that can significantly affect their corrosion behaviour [7], [9], [17]. The presence of hygroscopic products such as chlorides may significantly accelerate the corrosion processes, making the corrosion active 
even at a low RH values or in the presence of specific pollutants [7], [9], [18], [19].

Electric resistance (ER) sensors are based on electrical resistance measurements that are performed periodically. The time-variation of ER measurements can be correlated with the instantaneous corrosion rate. However, in order to fully represent how environmental conditions affect real works of art, an ER-based sensor should be pre-corroded or pre-aged prior to exposure.

Therefore, in order to implement and optimise a more effective tool for the monitoring of the degradation effects, it became necessary to design and characterise a new setup for the realisation of pre-corroded sensors. In previous works, the authors developed a sensor that can be preliminarily corroded so as to emulate the actual state of conservation of the artwork to be monitored [9], [20]. The sensor is based on printed circuit board (PCB) technology and requires a measurement system performing an electrical resistance tracking over time. However, the optimisation of the sensor and the study of specific corrosion processes require a huge amount of laboratory endeavours supported by high accuracy measurements and controlled environments.

In this paper, our developed measurement system and its metrological characterisation is presented. The system was designed to guarantee high measurement performance, flexibility, and modularity, as well as a good number of acquisition channels and ease of use. The metrological characterisation allows us to optimise the parameters of the measurement system so as to achieve the best performance.

A complete metrological characterisation of the measurement system and the developed sensor is described. Specifically, the effectiveness of the temperature compensation on pre-corroded and non-pre-corroded sensors is reported. Moreover, the effect of the uncertainty of the measurement system on the evaluation of the corrosion of the sensor is also investigated. Finally, an initial test of the corrosion monitoring via pre-corroded copperbased sensors in high humidity conditions is reported.

\section{SENSOR DEVELOPEMENT}

The development of the sensor was driven by the aspects of cost, flexibility, exposed surface area, measurement system characteristics, and sensitivity. Specifically, the developed sensor had to guarantee the following:

- the high surface area is representative of actual corrosion conditions,

- there is an appropriate distance between the traces to avoid the presence of short circuit bridges due to the formation of corrosion products,

- there is the possibility of reconfiguration through changing the sensor resistance value,

- it allows for performing a temperature compensation of the resistance variation due to thermal drift,

- low cost of production.

Based on the above constraints, a PCB solution was adopted. Here, the sensor was designed in four sections, two for each face of the PCB (Figure 1), to allow for the analysis of different measurement techniques and for implementing temperature compensation. In this work, terminal E and E' were connected to ensure a full PCB face was exposed to corrosion. Meanwhile, one face was protected from corrosion and was adopted as the reference for the temperature compensation (reference resistance: $R_{R}$ ), while the other face was subjected to corrosion
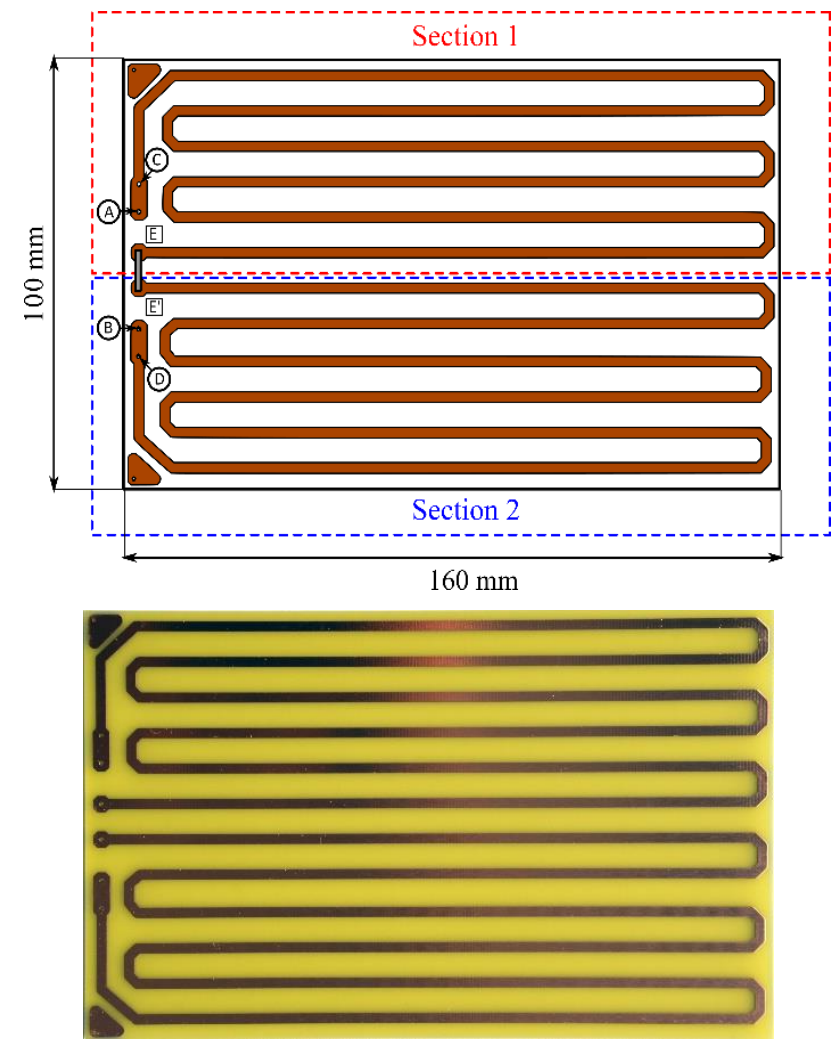

Figure 1. Schematic and photograph of the sensor layout.

(corrosion resistance: $\mathrm{RC}$ ). The geometrical parameters of the sensor were selected as shown in Figure 1. The tracks were made of copper to allow for the monitoring of copper-based objects, and had a rated thickness of $17 \mu \mathrm{m}$, meaning each face of the sensor had a rated value of $0.317 \Omega$. The PCB substrate was made of FR4 and had a thickness of $1.6 \mathrm{~mm}$.

In the preliminary design phase, we considered different environmental conditions leading to different corrosion rates ranging from $100 \mu \mathrm{m} /$ year (representing highly polluted and aggressive outdoor environments) to $5 \cdot 10^{-3} \mu \mathrm{m} /$ year (representing controlled environments with low levels of $\mathrm{RH}$ and pollutants).

The corrosion rate ( $\mu \mathrm{m} /$ year) was defined by assuming that the corrosion was uniform on the sensor surface. This means that by monitoring the thickness of the sensor, it should be possible to estimate the corrosion processes at the same time. Now, let us consider the expression of the resistance in terms of resistivity $\varrho$ and the geometrical parameters:

$$
R=\rho \frac{L}{S}=\rho \frac{L}{h \delta}
$$

where, $L, h, \delta$ are the total length, the width, and the thickness of the PCB tracks, respectively. Here, there exists an inversely proportional relationship between the resistance of the sensor and its thickness. Therefore, by monitoring the variation of the sensor resistance, it was possible to obtain information regarding the corrosion rate. Moreover, it became clear that the choice of track thickness will directly affect the sensitivity and lifetime of the sensors. Therefore, the design of the sensor was optimised in terms of lifetime and sensitivity for a specified level of corrosion rate, within a reasonable range of variation.

By measuring the $R_{R}$ and $R_{C}$, it was possible to compensate the thermal drift of the resistance's values - which is due to the 
environment temperature variations - by computing the ratio between the two resistive values for a generic temperature $T$ :

$$
K_{C}=\frac{R_{C}}{R_{R}}=\frac{R_{C 0}\left(1+\alpha\left(T-T_{0}\right)\right)}{R_{R 0}\left(1+\alpha\left(T-T_{0}\right)\right)}=\frac{R_{C 0}}{R_{R 0}}
$$

where $R_{C 0}$ and $R_{R 0}$ are the corrosion and the reference resistance values at temperature $T_{0}$, respectively, and $\alpha$ is the thermal coefficient of the conductive material of the PCB tracks. The assumption for a good compensation is that $a$ is the same for both resistances.

Assuming that the corrosion acts only on the $R_{C}$ track and that it is uniform, it is possible to define the relative variation of the thickness between a generic time $t$ and a reference time $t_{0}$ :

$$
\gamma(t)=\frac{\delta_{C}\left(t_{0}\right)-\delta_{C}(t)}{\delta_{C}\left(t_{0}\right)}=\frac{\Delta(t)}{\delta_{C}\left(t_{0}\right)}
$$

Therefore, $K_{C}$ at the generic time $t$ is independent of the temperature $\mathrm{T}$ and can be defined as follows:

$$
K_{C}(t)=\frac{L_{C}}{h_{C} \delta_{C}\left(t_{0}\right)(1-\gamma(t))} \frac{h_{R} \delta_{R}}{L_{R}}
$$

where $\gamma(t)$ is the relative reduction of the track thickness, $L, h$, $\delta$ are the total length, width and thickness of the PCB tracks, respectively, and the subscripts $R$ and $C$ are the reference and corrosion resistances, respectively. By normalising $K_{C}(t)$ in terms of its value at the reference time $t_{0}$, it is possible to estimate the variation of the thicknesses and hence the corrosion rate:

$$
C(t)=\frac{K_{C}(t)}{K_{C}\left(t_{0}\right)}=\frac{R_{C}(t)}{R_{R}(t)} \frac{R_{R}\left(t_{0}\right)}{R_{C}\left(t_{0}\right)}=\frac{1}{1-\gamma(t)}
$$

Moreover, the absolute thickness reduction can be computed, provided the initial track thickness $\delta_{C}\left(t_{0}\right)$ is known:

$$
\begin{gathered}
\Delta(t)=\delta_{C}\left(t_{0}\right)-\delta_{C}(t)=\left(1-\frac{1}{C(t)}\right) \cdot \delta_{C}\left(t_{0}\right)= \\
=\left(1-\frac{R_{C}\left(t_{0}\right)}{R_{R}\left(t_{0}\right)} \frac{R_{R}(t)}{R_{C}(t)}\right) \cdot \delta_{C}\left(t_{0}\right)
\end{gathered}
$$

Naturally, the minimum detectable variation of $\Delta(t)$ strongly depends on the resolution and the accuracy of the instrument used to perform the resistance measurements. In fact, by considering the measurement uncertainty of the instrument and the measurement procedure, the uncertainty on the evaluation of $\Delta(t)$ can be defined.

As described in the next section, all resistances were measured using the same digital multi-meter (DMM), the measurement accuracy of which is defined by the common binomial equation:

$$
a(R)= \pm(X \text { ppm of reading }+Y \text { ppm of range })
$$

This expression considers the effect of the noise and the nonideality of the instrument for non-correlated measurements. It is clear that, given the measurement process based on the ratio of the two measured resistances, the estimation of the measurement uncertainty must involve some consideration of the correlation between the measurements. In fact, the correlation reduces the uncertainty in the evaluation of $C(t)$.
For each resistor, the true value $R$ is known only through a measurement process, while since the instrument could be affected by a gain error $\Delta H$, the measurement model that relates the measured value $R_{m}$ to $R$ is the following:

$$
R_{m}=(1+\Delta H) R+\Delta R
$$

where:

- $\Delta H$ is a zero mean random variable that models the calibration error of the multimeter. Since it slowly changes in time, temporally close extractions are completely correlated (therefore, it is not reduced via repeated measures) while its correlation decreases when temporally distant extractions are considered, thus, due to the effect of the drifts, they can be regarded as independent.

- $\Delta R$ is a random variable with a mean value of zero that models the impact of the instrument noise. The variance due to the noise $\sigma^{2}(R)$ can be estimated using a category A approach and/or the constant term of the binomial formula of the multimeter. The extractions can always be regarded as independent.

By substituting Eq. (8) in Eq. (5), we can obtain the following:

$C(t)=\frac{N}{D}$

where the numerator and denominator of (9) can be written as follows:

$$
\begin{aligned}
N= & {\left[\Delta R_{C}(t)+(1+\Delta H(t)) R_{C}(t)\right] . } \\
& {\left[\Delta R_{R}\left(t_{0}\right)+\left(1+\Delta H\left(t_{0}\right)\right) R_{R}\left(t_{0}\right)\right] } \\
D= & {\left[\Delta R_{R}(t)+(1+\Delta H(t)) R_{R}(t)\right] . } \\
& {\left[\Delta R_{C}\left(t_{0}\right)+\left(1+\Delta H\left(t_{0}\right)\right) R_{C}\left(t_{0}\right)\right] }
\end{aligned}
$$

By neglecting the second-order products in Eqs. (10) and (11), Eq. (9) can be written as follows:

$$
\begin{array}{r}
C(t)=\frac{R_{R}\left(t_{0}\right) R_{C}(t)}{R_{R}(t) R_{C}\left(t_{0}\right)}\left[1+\Delta H(t)+\Delta H\left(t_{0}\right)+\frac{\Delta R_{C}(t)}{R_{C}(t)}+\right. \\
+\frac{\Delta R_{R}\left(t_{0}\right)}{R_{R}\left(t_{0}\right)}-\Delta H\left(t_{0}\right)-\Delta H(t)-\frac{\Delta R_{C}\left(t_{0}\right)}{R_{C}\left(t_{0}\right)}+ \\
\left.-\frac{\Delta R_{R}(t)}{R_{R}(t)}\right] \\
C(t)=\frac{R_{R}\left(t_{0}\right) R_{C}(t)}{R_{R}(t) R_{C}\left(t_{0}\right)}\left[1+\frac{\Delta R_{C}(t)}{R_{C}(t)}+\frac{\Delta R_{R}\left(t_{0}\right)}{R_{R}\left(t_{0}\right)}\right. \\
\left.-\frac{\Delta R_{C}\left(t_{0}\right)}{R_{C}\left(t_{0}\right)}-\frac{\Delta R_{R}(t)}{R_{R}(t)}\right]
\end{array}
$$

Meanwhile, the standard deviation of parameter $C(t)$ can be computed as follows:

$$
\sigma_{C}=\frac{R_{R}\left(t_{0}\right) R_{C}(t)}{R_{R}(t) R_{C}\left(t_{0}\right)}\left[\sqrt{\left(\frac{1}{R_{C}(t)}\right)^{2}+\left(\frac{1}{R_{R}\left(t_{0}\right)}\right)^{2}+\left(\frac{1}{R_{C}\left(t_{0}\right)}\right)^{2}+\left(\frac{1}{R_{R}(t)}\right)^{2}}\right] \sigma_{R}
$$


where $\sigma_{\mathrm{R}}$ can be evaluated via a category A approach.

Finally, the standard uncertainty on the thickness variation evaluation can be estimated as follows:

$u(\Delta(t))=\sqrt{\left(1-\frac{1}{C(t)}\right)^{2} \sigma^{2}\left(\delta_{C}\left(t_{0}\right)\right)+\left(\frac{-\delta_{C}\left(t_{0}\right)}{C(t)^{2}}\right)^{2} \sigma^{2}(C(t))}$

\section{MEASUREMENT SETUP}

In order to appropriately characterise the proposed sensor, a VI-based measurement system was developed (Figure 2). As noted above, the measurement setup must guarantee good measurement performance, flexibility, and modularity, as well as a good number of acquisition channels and ease of use.

A Keithley 3706 was used for performing the required 4-wire resistance measurements. As such, no contact resistances were included in the resistance measurements. The Keithley instrument was chosen since it provides a multi-channel measurement solution by means of switching cards, which means different pre-corroded sensors can be tested with the same highresolution DMM as part of a cost-effective solution. In fact, each switching card can perform 204 -wire resistance measurements. The 4-wire configuration allows for compensating the additional resistances due to the cables, the switching card, and the connection. The Keithley 3706 incorporates six slots, which means 120 resistance measurements can potentially be acquired with one DMM. In this work, only one switching card was connected.

For each tested sensor, three resistance measures were required: the resistance of the track exposed to corrosion, the resistance of the track used as reference for the temperature compensation, and the resistance of the pt100 temperature sensor. Given this requirement, the measuring system has the capacity to accommodate six sensors for characterisation.

Each single measure presented is the result of ten averaged measurements performed over five power line cycles (PLCs). The minimum analysis time for each sensor was $18 \mathrm{~s}$. These limits and configuration parameters were defined on the basis of the measuring system characterisation that is reported in the following section.

For each measure, the mean value and its standard deviation were computed and subsequently saved on a $\log$ file. The graphical interface of the developed measuring system is

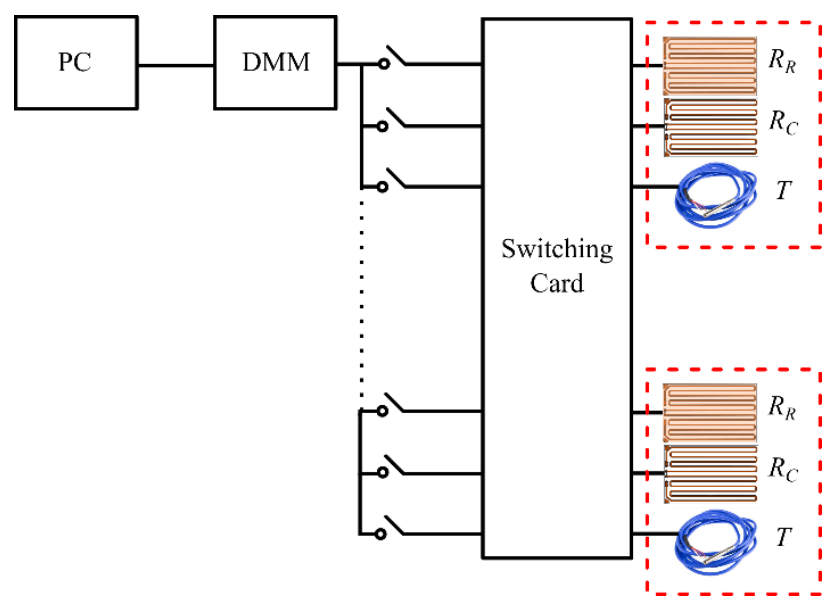

Figure 2. The measurement system architecture.

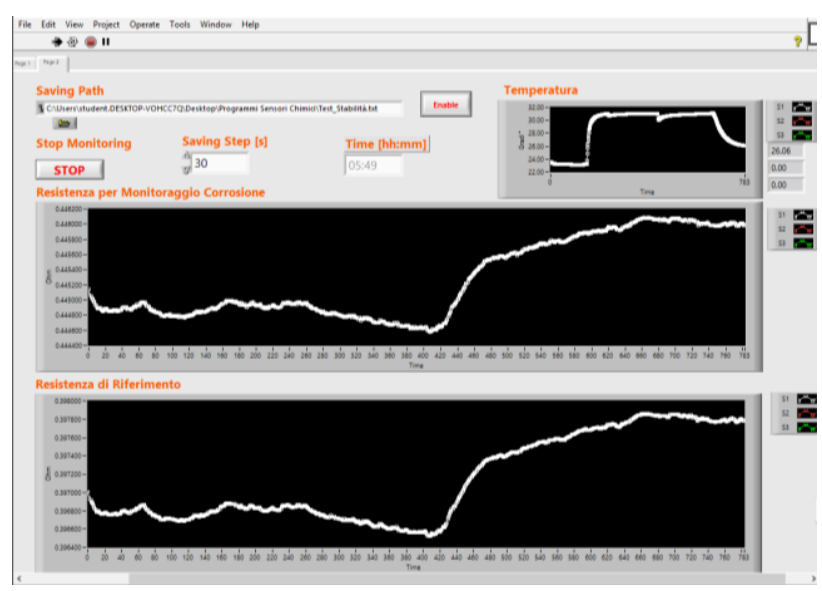

Figure 3. The VI front panel.

presented in Figure 3. The interface was made up of a configuration panel that allowed for setting the instrument parameters, as well as a measurement panel on which the measurements of the resistances over time were displayed.

\section{MEASUREMENT SYSTEM CHARACTERISATION}

In order to evaluate the accuracy and sensitivity of the measurement system, a series of tests were performed. First, the measurement noise of the system was evaluated by performing a measurement campaign on a standard resistance $R_{S}=0.1 \Omega$, characterised by a low thermal coefficient and placed into a climatic chamber that guaranteed a temperature of $23.0^{\circ} \mathrm{C} \pm$ $0.2^{\circ} \mathrm{C}$. The temperature was monitored using a digital thermometer (Dostman Electronics model P655-LOG) with a pt100 sensor. Meanwhile, a second channel was used for measuring the resistance of one face of the developed sensor placed in the same climatic chamber. The current was injected from terminal A and collected at terminal B (see Figure 1), while the voltage drop was measured between terminals $\mathrm{C}$ and $\mathrm{D}$. This allowed for evaluating the noise related to the sensor geometry and connections. The experimental setup is presented in Figure 4.

The DMM range was set to $1 \Omega$, which was appropriate for both the standard resistance and the developed sensor, while the dry circuit and offset compensation features were enabled. The DMM used in a 4-wire resistance configuration allows for setting the measurement time in terms of number of PLCs (NPLC). Moreover, the time between the closing operation of the switching card and the DMM activation can be controlled, with the intentional delay time $T_{D}$ used to ensure that the resistance measurements are performed when the system is in a steady state condition. In order to optimise the DMM parameters, different tests were performed on the standard and the sensor resistances. A total of 100 measurements were performed for both channels, with a $T_{D}$ ranging from 0 to $10 \mathrm{~s}$ and an NPLC deemed as equal

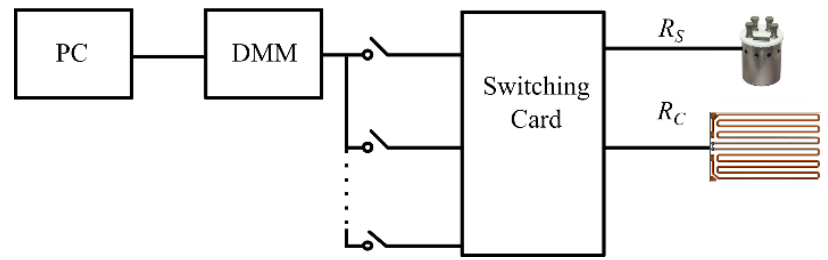

Figure 4. Measurement system characterisation setup. 


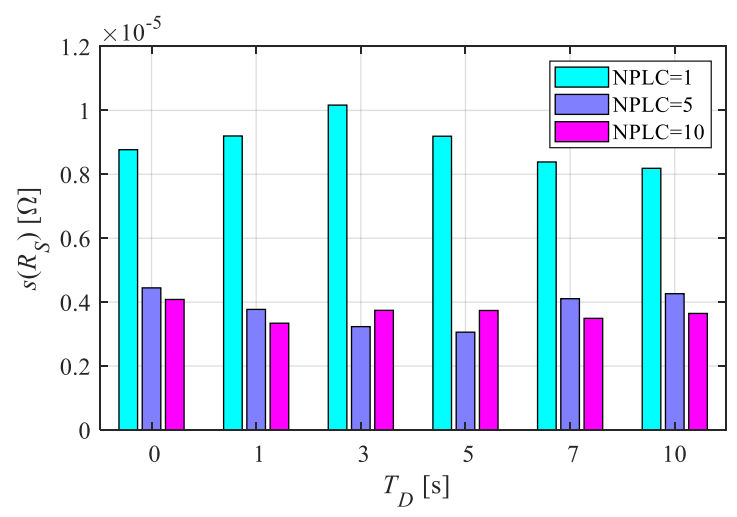

Figure 5. Standard deviation of $R_{S}$ in different test conditions.

to 1,5 , or 10 . The standard deviation was then computed for both the standard resistance $R_{S}$ and the sensor resistance $R_{C}$ in each test condition:

$$
s(R)=\sqrt{\frac{1}{N-1} \sum_{n=1}^{N}\left|R^{[n]}-R_{\mathrm{avg}}\right|^{2}}
$$

The results are presented in Figure 5 and Figure 6 for different $T_{D}$ and NPLC values.

Focusing on the standard deviation of $R_{S}$, it was clear that when NPLC = 1 was considered, the overall uncertainty was much higher than with NPLC $=5$ and NPLC $=10$ (approximatively double). Meanwhile, when no $T_{D}$ was considered, a higher standard deviation value was observed. Therefore, it can be stated that the best trade-off between measurement time and uncertainty was obtained with NPLC = 5 , as was expected given the instrument's datasheet [22]. In terms of the sensor resistance $R_{C}$, higher standard deviation values were observed in all cases, while a similar trend was evident. Thus, for each $T_{D}$, the best results were achieved with $N P L C=5$. In fact, when NPLC $=10$, that is, double the observation time, no significant improvements in terms of standard deviation were achieved.

Focusing on the data for NPLC $=5$, it was important to check whether the resistance measurements were performed in a steady state condition for each $T_{D}$. The attendant measurement results for the standard are presented in Figure 7, while those for the sensor resistances are presented in Figure 8.

In terms of the standard resistance $R_{S}$, it was clear that when no delay was set, there existed a transient effect that extended across around 10 measurement points. This transient effect could be mitigated by increasing the TD. However, in terms of

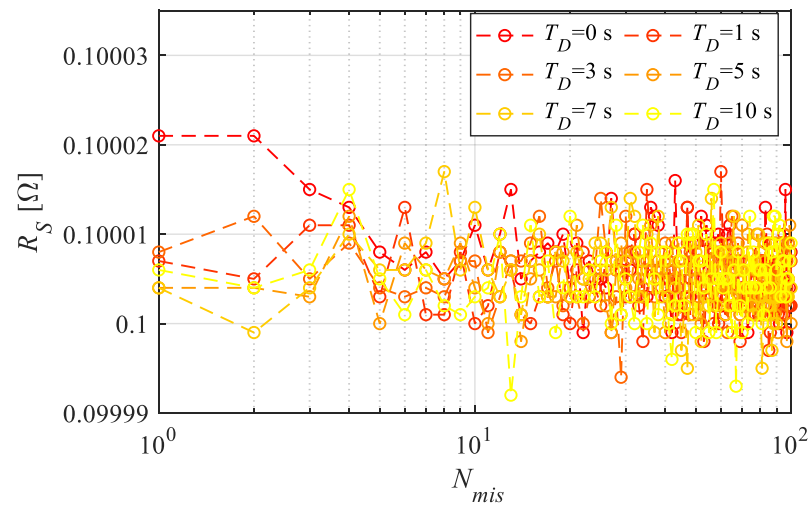

Figure 7. Measurements of $R_{S}$ for NPLC $=5$ and different $T_{D}$ values.

the sensor resistance $R_{C}$, this behaviour was more evident and a $\mathrm{T}_{\mathrm{D}}$ of at least $3 \mathrm{~s}$ had to be considered to prevent the emergence of the transient effects. These differences in dynamic behaviour can be attributed to the different impedance of the two channels.

Finally, it can be stated that the best trade off in terms of accuracy and time was achieved with $T_{D}=5 \mathrm{~s}$ and NPLC $=5$, with the standard deviation on the standard resistance reaching a value of $3.7 \cdot 10^{-6} \Omega$ and the sensor resistance reaching a value of $8.7 \cdot 10^{-6} \Omega$ under these conditions. This difference can be attributed to the design of the PCB sensor and to other environmental noise sources. As a final point on the measurement noise analysis, the standard uncertainty had to be determined in terms of the average value of $R_{C}$ across all 100 measurements:

$$
u_{A}\left(R_{C}\right)=s\left(R_{C, \text { avg }}\right)=\frac{s\left(R_{C}\right)}{\sqrt{N}},
$$

which resulted in $8.7 \cdot 10^{-7} \Omega$.

\section{EXPERIMENTAL RESULTS}

The proposed measurement system was developed to evaluate the sensitivity of the developed sensor to different environmental conditions. As noted above, one face of each sensor was protected from the corrosion using three layers of Incralac, an acrylic-based protective coating, which ensured the temperature compensation as described in the previous section. To evaluate the efficiency of the proposed compensation, a measurement campaign was performed. Specifically, four

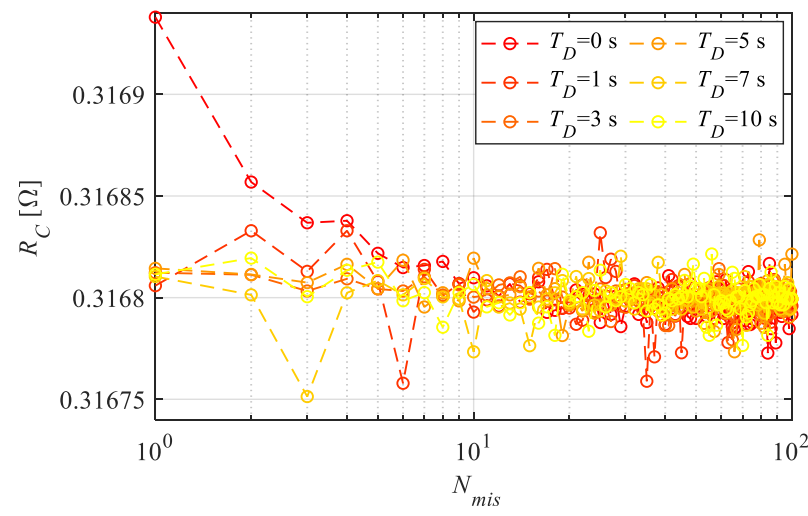

Figure 8. Measurements of $R C$ for $N P L C=5$ and different $T_{D}$ values. 


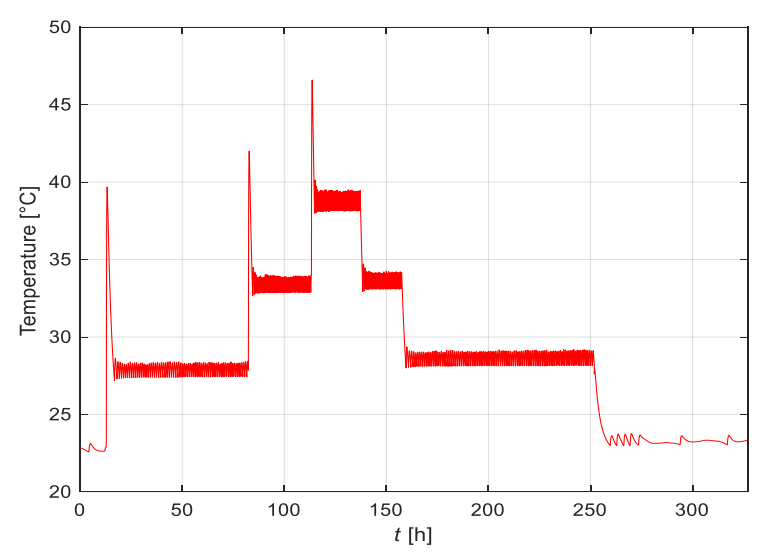

Figure 9. Temperature over time.

sensors (S01, S02, S03, and S04) were tested. Here, a layer of cuprite $\left(\mathrm{Cu}_{2} \mathrm{O}\right)$ was realised on $\mathrm{S} 01$, while a chloride and sulphate-based patina was realised on $\mathrm{S} 02$, with the remaining two sensors not pre-corroded. All sensors were left to corrode at $98 \% \mathrm{RH}$ for around one month prior to the characterisation. Here, the main aim was to produce artificial patinas with a composition that was representative of the corrosion products commonly found on the surfaces of cultural heritage objects. The cuprite patina was selected since it is generally the first corrosion product that forms on copper alloys [23]-[27]. Meanwhile, the chloride and sulphate-based patina was selected to reproduce the surface conditions of highly unstable artefacts from a corrosion point of view [7].

Before considering the performance of the developed sensor in the corrosion monitoring, it was crucial to verify the efficiency of the temperature compensation in different corrosion conditions of the sensors. Therefore, the sensors were placed in a climatic chamber, with the RH kept below $20 \%$ to ensure negligible corrosion rates [8]. A temperature profile was then set and monitored using the pt100. Here, the sensors and the pt100 were carefully placed in the chamber so as to reduce the effects due to the thermal gradient during the warming up process. The temperature was changed from a minimum of $23{ }^{\circ} \mathrm{C}$ to a maximum of $39{ }^{\circ} \mathrm{C}$, as shown in Figure 9. Due to the control system of the climatic chamber, the temperature profile was characterised by overshooting during the warming up phase and

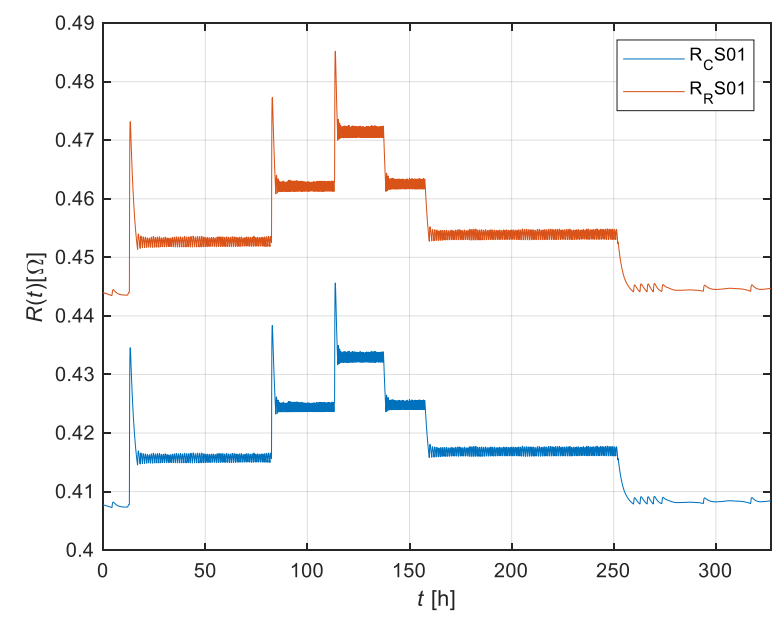

Figure 10. Sensor resistances over time.

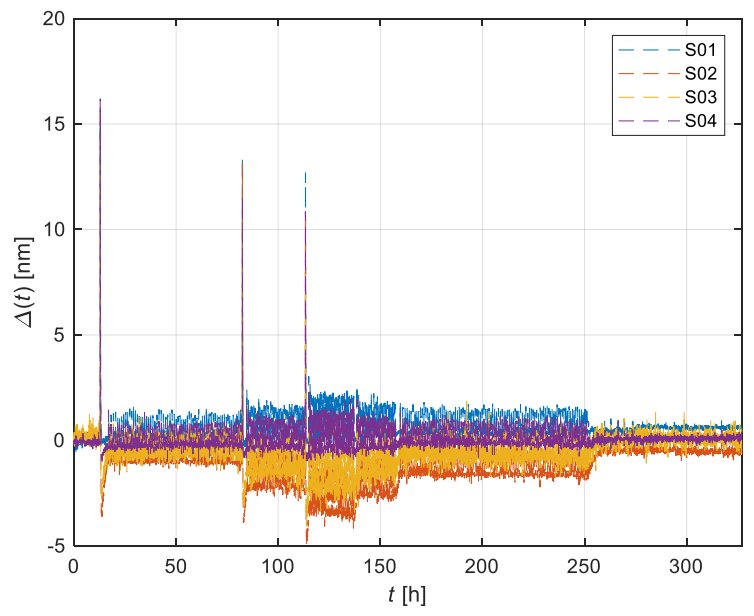

11. The $\Delta(t)$ over time for sensors S01, S02, S03 and S04.

by a temperature ripple of around $1.2{ }^{\circ} \mathrm{C}$ with a frequency of 30 min during the phase of maintaining the temperature.

The developed measurement system was used to monitor the sensors, S01, S02, S03, and S04, for around 320 h. For each sensor, the two resistive values, $R_{C}$ and $R_{R}$, were measured. As expected, the temperature variation provoked a non-negligible change in sensor resistance (Figure 10).

As previously described, this effect can be compensated by computing the parameter $C(t)$ according to Eq. (5). This parameter allowed for evaluating the thickness reduction as described in Eq. (6). 11 shows the $\Delta(t)$ computed for each sensor, with the attendant fluctuation indicating that there was a temperature mismatch between the two faces of the sensors during the environment temperature variation. Specifically, it was clear that the rapid temperature ripple of $1.2^{\circ} \mathrm{C}$ caused a fluctuation in $\Delta(t)$ of around $2 \mathrm{~nm}$.

In order to remove this effect, a moving average filtering of the data could be performed. Based on the temperature oscillation, as well as some consideration of the sensor application, an average time window of $1 \mathrm{~h}$ was chosen. Figure 12 presents the results of the filtering process, where it was clear that the temperature compensation depended on the sensors.

Overall, the experimental results demonstrated that the temperature compensation achieved a good performance. In

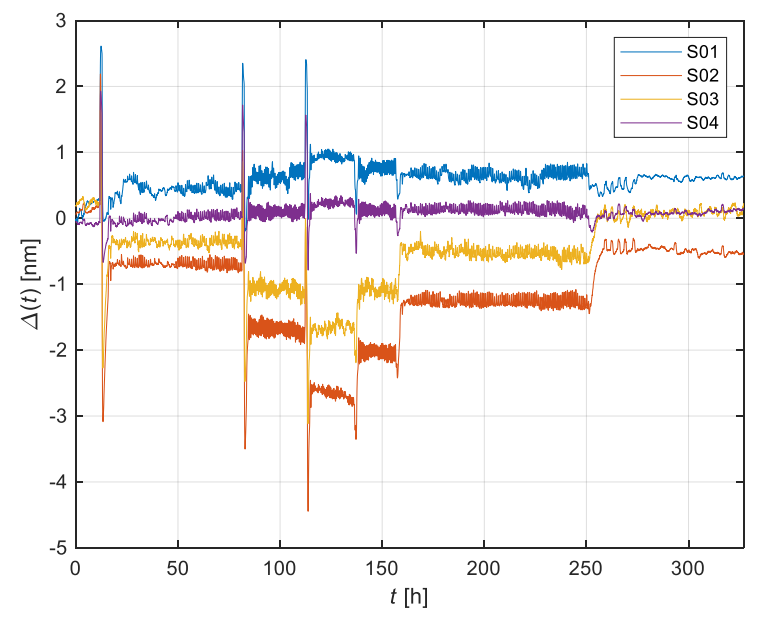

Figure 12. The filtered $\Delta(t)$ for sensors S01, S02, S03 and S04. 


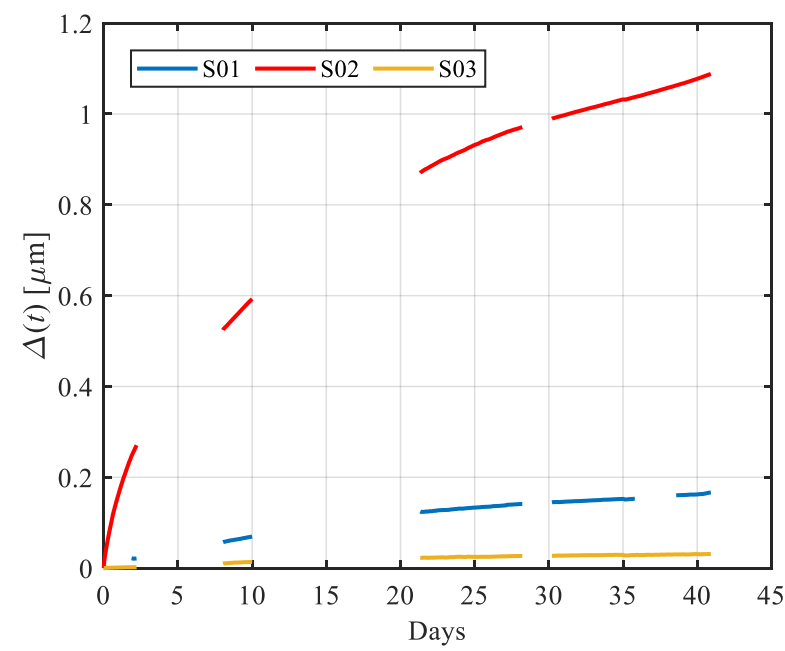

Figure 13. Preliminary results of the corrosion monitoring ( $\mathrm{RH} \geq 98 \%)$.

fact, the fluctuation in $\Delta(t)$ was in the order of $3 \mathrm{~nm}$ for a temperature variation of around $20{ }^{\circ} \mathrm{C}$. This value was higher than the uncertainty that was due to the measurement system, which, assuming a sensor thickness uncertainty of $10 \%$, was in the order of $0.3 \mathrm{~nm}$. This means that any corrosion producing a variation in $\Delta(t)$ over $3 \mathrm{~nm}$ can be attributed to the corrosion effects in the considered temperature range for the sensors in question.

Sensors S01, S02, and S03 were used to evaluate the increase in corrosion rate that occurs when the $\mathrm{RH}$ is increased to extremely high values $\left(\mathrm{RH} \geq 98 \%, 25 \pm 3{ }^{\circ} \mathrm{C}\right)$.

As Figure 13 shows, a sudden and relevant increase in corrosion rate was recorded across all the sensors as a consequence of the RH increase. The corrosion was calculated from the slope of the curves and, during the first two days, it was found to be around $5 \mu \mathrm{m} / \mathrm{y}$ for the sensor with the cuprite patina (S01), while a far more dramatic increase was observed up to a value of around $58 \mu \mathrm{m} / \mathrm{y}$ for the sensor with the chloride and sulphate-based patina ( $\mathrm{S} 02)$. The non-pre-corroded sensor $(\mathrm{S} 03)$ exhibited the lowest corrosion rate, which, during the first two days, was around $0.2 \mu \mathrm{m} / \mathrm{y}$. It was also clear that the corrosion rate tended to decrease with time (Figure 13), which suggested a gradual stabilisation of the surface over time.

The obtained results demonstrated that the sensors can track metal corrosion and that the acceleration of the corrosion rate is highly influenced by the presence and composition of the corrosion layers over the surface.

\section{CONCLUSIONS}

In this paper, the metrological characterisation of a measurement system designed for the development of sensors for the monitoring of the environmental corrosivity affecting copper-based artworks was presented. Furthermore, a sensor that allows for consideration of the presence of corrosion layers on historic surfaces was reported. The measuring system is characterised by good flexibility and modularity, and allows for performing measurements on up to 40 sensors. According to the results of the preliminary tests, the system appears to be highly promising. Specifically, the measurement uncertainty and the efficiency of the temperature compensation process was evaluated, with an accuracy of $3 \mathrm{~nm}$ within a temperature range of $23{ }^{\circ} \mathrm{C}-39{ }^{\circ} \mathrm{C}$ demonstrated. This means that the proposed corrosion sensors could be used for heritage preservation. The proposed system was then used to evaluate the impact of precorrosion on the corrosion rate of copper-based artefacts providing relevant information. The proposed system can be regarded as a promising solution for the development and characterisation of sensors for the monitoring of copper-based cultural heritage.

\section{REFERENCES}

[1] D. M. Bastidas, M. Criado, S. Fajardo, V. M. La Iglesia, E. Cano, J.M. Bastidas, Copper deterioration: causes, diagnosis and risk minimisation, International Materials Reviews 55 (2010), pp 99$127,2010$. DOI: $10.1179 / 095066009 \times 12506721665257$

[2] J. Tétreault, E. Cano, M. van Bommel, D. Scott, M. Dennis, M.G. Barthés-Labrousse, L. Minel, L. Robbiola, Corrosion of copper and lead by formaldehyde, formic and acetic acid vapours, Studies in Conservation 48 (2003), pp. 237-250. DOI: $\underline{10.1179 / \text { sic.2003.48.4.237 }}$

[3] La Gennusa, G.Rizzo, G.Scaccianoce, F. Nicoletti, Control of indoor environments in heritage buildings: experimental measurements in an old Italian museum and proposal of a methodology, Journal of Cultural Heritage 6 (2005), pp. 147-155. DOI: $10.1016 /$ j.culher.2005.03.001

[4] D.De la Fuente, J.M.Vega, F.Viejo, I.Díaz, M.Morcillo, Mapping air pollution effects on atmospheric degradation of cultural heritage, Journal of Cultural Heritage 14 (2013), pp. 138-145. DOI: $10.1016 /$ j.culher.2012.05.002

[5] G.M.Ingo, E.Angelini, C.Riccucci, T.De Caro, A.Mezzi, F.Faraldi, D.Caschera, C.Giuliani, G.Di Carlo, Indoor environmental corrosion of Ag-based alloys in the Egyptian Museum (Cairo, Egypt), Applied Surface Science 326 (2015), pp. 222-235. DOI: $10.1016 /$ j.apsusc.2014.11.135

[6] M.Ryhl-Svendsen, Corrosivity measurements of indoor museum environments using lead coupons as dosimeters, Journal of Cultural Heritage 9 (2008), pp. 285-293. DOI: $10.1016 /$ j.culher.2008.01.005

[7] D.Thickett, R.Chisholm, P.Lankester, Reactivity monitoring of atmospheres, Metal 2013 - Interim Meeting of the ICOM-CC Metal Working Group, Edinburgh, Scotland, 2013, pp.129-135.

[8] S.Goidanich, D.Gulotta, L.Brambilla, R.Beltrami, P.Fermo, L.Toniolo, Setup of galvanic sensors for the monitoring of gilded bronzes, Sensors 14 (2014), pp. 7066-7083. DOI: $10.3390 / \mathrm{s} 140407066$

[9] L.Sjögren, N.L.Bozec, On-line corrosion monitoring of indoor atmospheres, EUROCORR, 2004, Nice, France. DOI: $10.1533 / 9781845693015.293$

[10] C. Petiti, M. Faifer, M. Zanoni, S. Goidanich, ER-Based sensors for monitoring atmospheric corrosivity on corroded or patinated copper-based objects, METAL 2019 - Proceedings of the Interim Meeting of the ICOM-CC Working Group on Training in Conservation and Restoration, Neucâtel, Switzerland, 2-6 September, 2019.

[11] I. Shitanda, A. Okumura, M. Itagaki, K. Watanabe, Y. Asano. Screen-printed atmospheric corrosion monitoring sensor based on electrochemical impedance spectroscopy, Sensors and Actuators B: Chemical 139 (2009), pp. 292-297. DOI: $10.1016 /$ j.snb.2009.03.027

[12] D. Mizuno, S. Suzuki, S. Fujita, and N. Hara, Corrosion monitoring and materials selection for automotive environments by using Atmospheric Corrosion Monitor (ACM) sensor, Corrosion Science 83 (2014), pp. 217-225. DOI: $10.1016 /$ j.corsci.2014.02.020

[13] A. Nishikata., Q. Zhu, E. Tada, Long-term monitoring of atmospheric corrosion at weathering steel bridges by an electrochemical impedance method, Corrosion Science 87 (2014), pp. 80-88. 
DOI: $10.1016 /$ i.corsci.2014.06.007

[14] T. Prosek, M. Kouril, M. Dubus, M. Taube, V. Hubert, B. Scheffel, Y. Degres, M. Jouannic, D. Thierry, Real-time monitoring of indoor air corrosivity in cultural heritage institutions with metallic electrical resistance sensors, Studies in Conservation 58 (2013), pp. 117-128.

DOI: $10.1179 / 2047058412 Y .0000000080$

[15] Henoc Agbota, John E. Mitchell, Marianne Odlyha, Matija Strlič, Remote assessment of cultural heritage environments with wireless sensor array networks, Sensors 14 (2014), pp. 8779-8793. DOI: $10.3390 / \mathrm{s} 140508779$

[16] J.P. Dracott, Piezoelectric printing and pre-corrosion: Electrical resistance corrosion monitors for the conservation of heritage iron, Faculty of Engineering and Physical Sciences, 2014, University of Manchester, Manchester.

[17] International Organization for Standardization. Corrosion of metals and alloys - Corrosivity of atmospheres - Classification, determination and estimation, 2012, (BS EN ISO 9223: 2012, last reviewed and confirmed in 2017)

[18] J. Tidblad, K. Kreislova, M. Faller, D. De la Fuente, T. Yates, A. Verney-Carron, Report no. 78 - Results of corrosion and soiling from the 2011-2015 exposure programme for trend analysis, Convention on Long-Range Transboundary Air Pollution. UN/ECE International Co-operative Programme on Effects on Materials, Including Historic and Cultural Monuments, 2016, Swerea KIMAB AB, Stockholm, Sweden, pp. 1-35.

[19] I. Odnevall Wallinder, X. Zhang, S. Goidanich, N. Le Bozec, G. Herting, C. Leygraf, Corrosion and runoff rates of $\mathrm{Cu}$ and three Cualloys in marine environments with increasing chloride deposition rate, Sci Total Environ 472 (2014), pp. 681-694. DOI: $10.1016 /$ i.scitotenv. 2013.11 .080

[20] D.A. Scott, Bronze disease: A review of some chemical problems and the role of relative humidity, J Am Inst Conserv. 29 (1990), pp. 193-206.

DOI: $10.1179 / 019713690806046064$

[21] M. Faifer, S. Goidanich, C. Laurano, C. Petiti, S. Toscani, M.
Zanoni, Measurement setup for the development of pre-corroded sensors for metal artwork monitoring, Proc. 2019 IMEKO TC4 International Conference on Metrology for Archaeology and Cultural Heritage, Florence, Italy, 4-6 December 2019, pp. 1-6. Online [Accessed 23 March 2021]

https://www.imeko.org/publications/tc4-Archaeo2019/IMEKO-TC4-METROARCHAEO-2019-106.pdf

[22] Series 3700A System Switch/Multimeter Reference Manual. Online [Accessed 30 September 2020] https://download.tek.com/manual/3700AS-90101C Jul 2016 Ref 3.pdf

[23] A. Krätschmer, I. Odnevall Wallinder, C. Leygraf, The evolution of outdoor copper patina, Corrosion Science 44 (2002), pp.425450. DOI: $10.1016 / \mathrm{S} 0010-938 \mathrm{X}(01) 00081-6$

[24] T. Chang, G. Herting, S. Goidanich, J. M. Sánchez Amaya, M. A. Arenas, N. Le Bozec, Y. Jin, C. Leygraf, I. Odnevall Wallinder, The role of $\mathrm{Sn}$ on the long-term atmospheric corrosion of binary $\mathrm{Cu}-\mathrm{Sn}$ bronze alloys in architecture, Corrosion Science 149 (2019), pp. 54-67.

DOI: $10.1016 /$ i.corsci.2019.01.002

[25] T. Chang, A. Maltseva, P. Volovitch, I. Odnevall C. Wallinder, Leygraf, A mechanistic study of stratified patina evolution on Snbronze in chloride-rich atmospheres, Corrosion Science 166 (2020), 108477, pp. 1-13. DOI: $\underline{10.1016 / \text { i.corsci.2020.108477 }}$

[26] C. Leygraf, T. Chang, G. Herting, I. Odnevall Wallinder, The origin and evolution of copper patina colour, Corrosion Science 157 (2019), pp. 337-346.

DOI: $10.1016 /$ i.corsci.2019.05.025

[27] Elisabetta Di Francia, Ruth Lahoz, Delphine Neff, Emma Angelini, Sabrina Grassini, Laser cleaning of Cu-based artefacts: laser/corrosion products interaction, Acta IMEKO, 7 (2018) 3, pp. 104-110.

DOI: $\underline{10.21014 / \text { acta imeko.v7i3.610 }}$ 